Wills' Australian employee, Suzanne Povey, was not intended to be critical of her candid concern for children's health. Instead we were amused by her antics when cornered with the implications of this concern. Like Povey, Dr Proctor admits it is "commonsense" not to smoke around children, but both are conspicuously reluctant to explain just why this is the case. What, exactly, is the problem with smoking around small children, Ms Povey and Dr Proctor?

DAVID SIMPSON News Editor

SIMON CHAPMAN Deputy Editor

\section{Clearing the air at the Red Cross}

EdrToR,-A news article in the Spring 1995 issue of Tobacco Control (1995;4:18-19) began as follows: "Of the following location in Winston-Salem, in the state of North Carolina, which, would you guess, is the one with the smoke-free environment-the YMCA, the American Red Cross Blood Donation Center, or the Krispy Kreme Donut Shop? Surprisingly, the only one of the three to ban smoking is also the one without a public health mission: the doughnut shop." I am happy to report that now all three have established no-smoking policies!

Reporting tobacco control news such as the original story in Tobacco Control about the
Winston-Salem Red Cross Center serves not only as a useful news exchange, but also as an intervention. The Winston-Salem Red Cross Center changed its policy as a result of correspondence with health professionals in the Winston-Salem area, and as a result of exposure in Tobacco Control. Copies of the article in Tobacco Control were disseminated widely after it was published.

If progress can be made in Winston-Salem, it can happen anywhere.

DArth Carolina Group to Alleviate Smoking Pollution (GASP) Central Region, PO Box 5974 Winston-Salem, North Carolina 27113-5974

email:dzaccaro@rc.phs.bgsm.edu

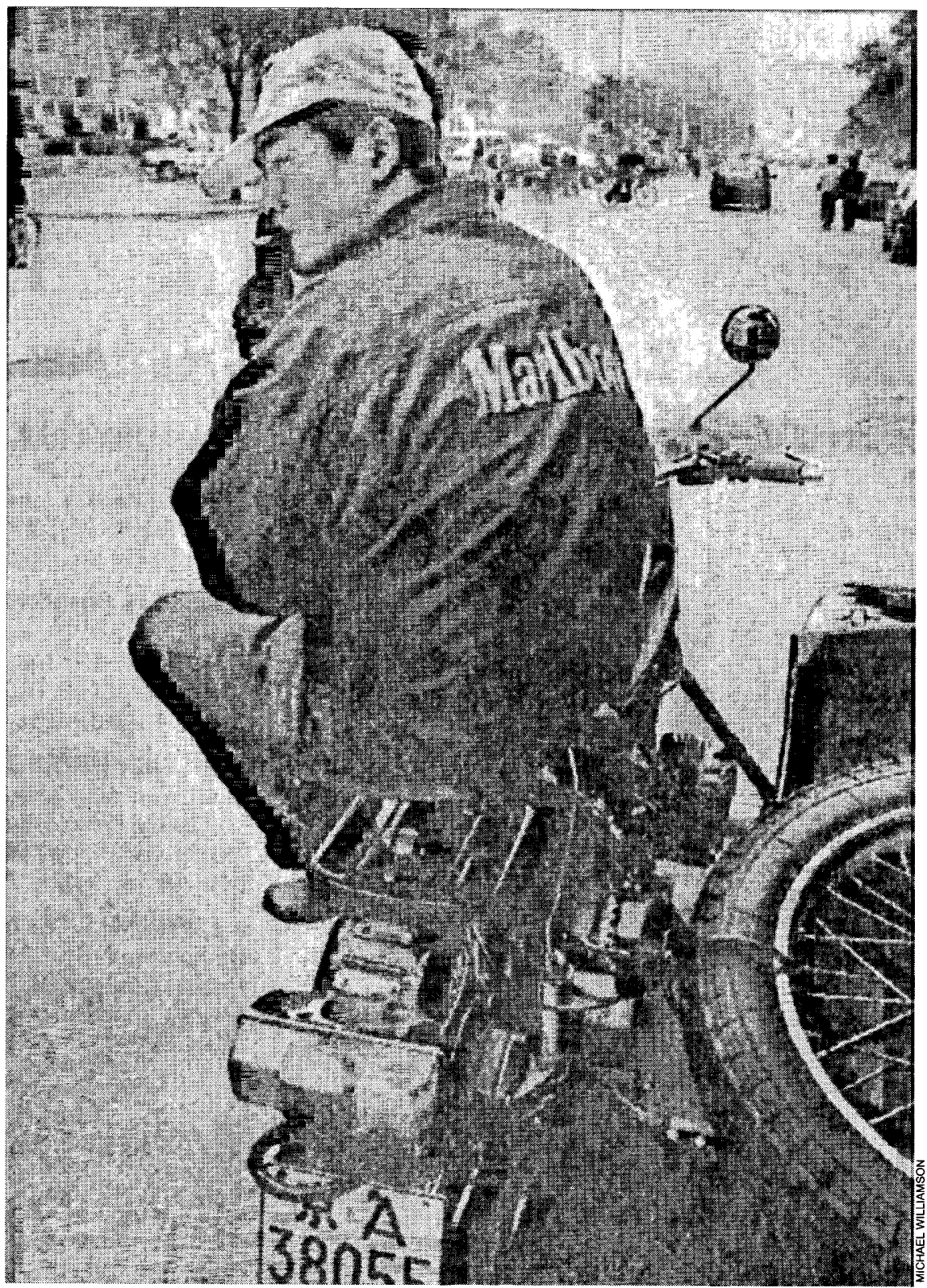

Alongside this photo, the Washington Post (17 November 1996) noted that "Clothing and other paraphernalia that advertise U.S. cigarette brands are symbols of sophistication and affluence throughout the newly opened markets in Asia."

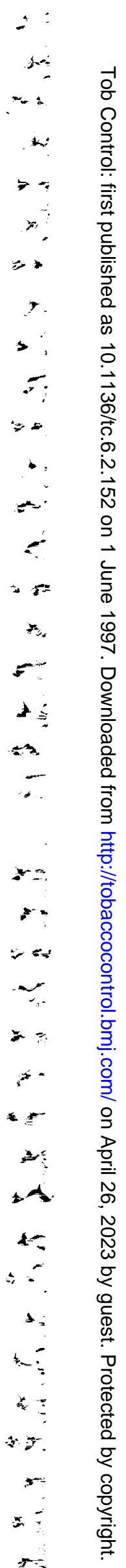

$-2$ 